ARTIGO

Recebido em: $22 / 09 / 2014$

Aceito em:

$27 / 11 / 2014$
Encontros Bibli: revista eletrônica de biblioteconomia e ciência da informação, v. 19, n.41, p. 83-104, set./dez., 2014. ISSN 1518-2924. DOI: 10.5007/1518-2924.2014v19n41p83

\section{Modelos e experiências de competência em informação em contexto universitário ${ }^{1}$ \\ Information literacy models and practices in university context}

Fernanda Maria Melo ALVES, 2

Adriana Rosecler ALCARÁ3

\title{
RESUMO
}

0 artigo indica alguns estudos diacrônicos de revisão e de comparação sobre competência em informação a nível mundial e investiga alguns modelos em contexto universitário e suas respectivas aplicações, descrevendo experiências realizadas com estudantes, em diferentes universidades e países. Para tanto, realizou-se uma pesquisa bibliográfica e documental. Entre os resultados destaca-se a diversidade cronológica e geográfica dos modelos, bem como as suas diversas possibilidades de aplicação para a avaliação e o desenvolvimento da competência em informação de universitários.

PALAVRAS-CHAVE: Competência em informação. Modelos de competência em informação. Estudantes universitários.

\begin{abstract}
The article indicates some diachronic studies review and comparison on information literacy worldwide and researches some models in university context and their applications, describing experiments with students in different universities and countries. To this end, we performed a bibliographic and documentary research. Among the findings, highlight the chronological and geographical diversity of the models, and their various possibilities of application to the evaluation and development of information literacy of students.
\end{abstract}

KEYWORDS: Information literacy. Information literacy models. University students.

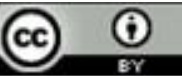

Esta obra está licenciada sob uma Licença Creative Commons.

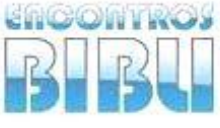

v. 19, n. $41,2014$. p. 83-104

ISSN 1518-2924
${ }^{1} 0$ presente artigo inicia uma investigação pós-doutoral sobre as necessidades de competência em informação dos profissionais de informação dos países africanos lusófonos (PALOP).

2 Universidade Estadual de Londrina - fmeloa2@hotmail.com

3 Universidade Estadual de Londrina - adrianaalcara@gmail.com 


\section{INTRODUÇÃo}

O conceito de competência em informação ou literacia de informação, cujo termo original em inglês é information literacy, não se compreende fora do contexto de que lhe é atribuído, desenvolvimento técnico e científico, principalmente, as indústrias de informação, as telecomunicações, a informática, a eletrônica, as comunicações móveis, a Internet, a digitalização, os sistemas de informação e a sua gestão aplicada às unidades de informação e à educação. As relações entre estes campos, as diferentes perspectivas, áreas e atividades permitiram que este conceito se tornasse polissêmico e polêmico.

Apesar de todos os esforços de teorização e práticas e das divergências conceituais e terminológicas, característicos do percurso científico, cuja necessidade e benefícios são incontestáveis, estamos perante um espaço científico relativamente recente, que congrega uma comunidade da qual se espera, num futuro próximo, a consolidação dos estudos alcançados, a normalização terminológica e o desenvolvimento da sua aplicação no campo da educação, delineando um tópico de investigação claro e estável.

Prefaciando o manual Towards Information Literacy Indicators (CATTS; LAU, 2008), Khan lembra que a Proclamação de Alexandria (2005) confere à competência-em informação o estatuto de direito humano básico no mundo digital, porque possibilita aos indivíduos em todas as circunstâncias da vida avaliar, usar e criar informação eficazmente, para atingir os seus objetivos pessoais, sociais, ocupacionais e educacionais. E acrescenta que as competências em informação devem ser consideradas não só em relação à educação, mas também ao desenvolvimento econômico e social das nações, à saúde e ao bemestar, bem como ao envolvimento e à participação ativa na sociedade.

A produção científica nesta área assinala a universalidade do paradigma de desenvolvimento de competências em informação para o século XXI e a necessidade da sua inclusão nos conteúdos dos diferentes níveis de educação ao longo da vida. Neste sentido, o European Conference on Information Literacy (ECIL 2014), realizado na Croácia, em Outubro de 2014, comemorou quatro décadas da aparição do termo Informational Literacy, cunhado pelobibliotecário 
americano Paul Zurkowski, mencionado no relatório intitulado The Information service environment relationships and priorities, publicado em 1994.

0 presente artigo propõe um estudo de modelos e aplicações em contexto universitário a nível mundial, alguns deles pouco divulgados, que relatam experiências realizadas em diferentes universidades e países.

\section{REFERENCIAL TEÓRICO}

Não é intenção desta pesquisa fazer uma análise exaustiva da origem e evolução do conceito e da terminologia usada no campo da competência em informação, já efetuada, de forma brilhante e regular por vários especialistas e organizações, para cuja produção científica se remete o leitor que deseje aprofundar o assunto. Apenas destacamos alguns estudos diacrônicos de revisão e de comparação, The New London Group (1996), Bhola, (1997), Bawden (2002), Virkus (2003), Duplessis et al. (2005), Calzada Prado e Marzal (2007), Le Deuff (2007), Markless e Streatfield (2007), Uribe-Tirado (2009), Marzal (2009), Pinto, Cordón e Gómez (2010), que proporcionam uma visão de conjunto e definem as principais linhas de investigação e práticas em diferentes contextos geográficos e linguísticos.

Também é conveniente ressaltar a periodização de décadas de trabalho desenvolvido nesta área (BEHRENS, 1994), proposta aceitada por Bernhard (1998), e confirmada, no contexto iberoamericano, por Dudziak (2003) e por Uribe-Tirado e Uribeii (2011). Todos apontam para uma nova fase, posicionamento ou redefinição, desencadeada, em parte, pelo aparecimento das mídias sociais e das comunidades colaborativas em linha, e pela configuração de novas perspectivas (LIMBERG; SUNDIN; TALJA, 2012; MORING; LLOYD, 2013). A este propósito, Mackey e Jacobson (2011) afirmam que esta redefinição expande o escopo do conceito de competência em informação e coloca uma ênfase particular na produção e compartilhamento de informações em ambientes digitais participativos.

O Colóquio realizado na Biblioteca de Alexandria em 2005, organizado pela UNESCO, IFLA e o National Forum on Information Literacy, produziu uma 
declaração, The Alexandria Proclamation on Information Literacy and Lifelong Learning, na qual se assume que a competência em informação e a aprendizagem ao longo da vida são os Faróis da Sociedade da Informação, iluminando os caminhos para o desenvolvimento, a prosperidade e a liberdade. A competência em informação capacita as pessoas para buscar, avaliar, usar e criar a informação de forma efetiva para atingir as suas metas pessoais, sociais, ocupacionais e educacionais e é um direito humano básico num mundo digital e promove a inclusão social em todas as nações (UNESCO/ IFLA, 2005). Nesse sentido, as recomendações do manual Guidelines on information literacy for lifelong learning, publicado pela IFLA (2006) indicam como competências informativas gerais: 1. Acesso. a) Necessidade: decisão, expressão, início. b) Localização: busca, seleção, localização. 2. Avaliação. a) Avaliação: análise, generalização, valorização. b) Organização: categorização, estruturação, ordenamento. 3. Uso. a) Uso de informação: aplicação, aprendizagem, utilização. b) Comunicação: uso ético, reconhecimento, estilo/padrões.

As orientações da UNESCO (2008) e da IFLA (2008) para a formação de competência em informação e midiática, em inglês Media and Information Literacy (MIL), destinadas a promover a igualdade de acesso à informação e ao conhecimento, à mídia e aos sistemas de informação livres, independentes e pluralistas, reúnem: a) As competências informacionais (mobilização de conhecimentos, habilidades e atitudes relacionadas com o universo informacional, capacidade de leitura e escrita, busca e uso da informação, organização e manipulação de dados visando a produção de novas informações e conhecimentos, sua disseminação e preservação visando o seu reuso futuro); b) E as competências midiáticas (convergência de conhecimentos, habilidades e atitudes, em relação ao uso e compreensão dos meios e processos de comunicação de massa, que ocorre em estados avançados de desenvolvimento da sociedade).

A referida proposta centra-se em cinco competências básicas, conhecidas como as 5Ces: compreensão, pensamento crítico, criatividade, consciência intercultural e cidadania. 
Consideramos sensata esta atitude integradora das duas organizações, que inclui numerosas propostas, resultantes de diferentes características ou dimensões, complementares entre si, e que abarca uma visão múltipla e global.

No contexto universitário, Paulette Bernhard (2000) expõe algumas razões que justificam a necessidade de potenciar as competências em informação:

- o crescimento exponencial de informações disponíveis e acessíveis em qualquer formato;

- a informação cada vez mais heterogênea, cuja autenticidade, validade e credibilidade devem ser confirmadas continuamente;

- uma economia fortemente baseada em atividades de serviços, apelando a tecnologias em rápido desenvolvimento;

- a necessidade de se adquirir e desenvolver habilidades transferíveis e utilizáveis ao longo da vida, e aprender numa perspectiva de solução de problemas;

- a necessidade absoluta de estar atualizado sobre os desenvolvimentos mais recentes para as atividades de investigação;

- a procura dos empregadores, que querem contratar pessoas capazes de dominar tecnologias, buscar informação em fontes eletrônicas e na Internet e de avaliar e gerir a informação interna e externa, assim como realizar atividades de alerta;

- a evolução para uma pedagogia ativa centrada no estudante, com base na formação e na solução de problemas;

- o impacto da formação contínua no uso de informação e a obtenção do sucesso.

As competências em informação tornaram-se uma necessidade e uma exigência no ensino universitário, visto que os profissionais serão avaliados pelo seu conhecimento e pelo valor acrescentado que podem gerenciar, razão pela qual o principal desafio dos sistemas de educação é potencializar a aquisição, estruturação e organização do conhecimento e proporcionar-lhes um grande número de habilidades e competências para resolver problemas (PINTO, 2011). 
Por outro lado, as bibliotecas como centros de recursos de aprendizagem e relacionadas direta e intimamente com a aprendizagem, são, portanto, elemento imprescindível de uma pedagogia integradora, na qual se reconhece o papel fundamental do infoeducador, bibliotecários, professores e coordenadores, na mediação necessária para auxiliar os aprendizes a transformarem informação em conhecimento (GASQUE, 2012).

\section{METODOLOGIA}

Para o presente estudo realizou-se uma investigação bibliográfica e documental, durante a qual, na ausência de uniformidade terminológica, se utilizaram diferentes termos e línguas, information literacy, maîtrise de l'information, alfabetización informacional, ALFIN, literacia de informação, competência em informação e letramento informacional. A coleta de dados corresponde aos meses de março e abril de 2014.

A busca efetuou-se nas bases de dados ISI, SCOPUS, ERIC, LISA, ESMERALD, REDALYC, SCIELO e DIALNET, no buscador acadêmico Google Scholar, nos repositórios DOAJ, E-LIS e Scientic Commons. Eliminada a informação duplicada, reuniu-se um corpus, a partir do qual se efetuou a análise e seleção de documentos, de acordo com o propósito desta pesquisa.

\section{COMPETÊNCIAS EM INFORMAÇÃO EM CONTEXTO UNIVERSITÁRIO: MODELOS E EXPERIÊNCIAS}

Para orientar as estratégias para o desenvolvimento da competência em informação, produziu-se um conjunto de recursos, que abrangem normas, modelos, indicadores de desempenho, avaliações, manuais de boas práticas, encontros científicos, programas e projetos, tendo subjacente a adoção de uma pedagogia de solução de problemas, de descoberta e de sucesso.

As influências conceituais que agem sobre a conduta informativa acabam por determinar diferentes concepções, a convivência simultânea dessas várias concepções e modelos, dependendo do destaque, contexto e experiência. Os 
modelos podem ter nomes diferentes, mas representam processos semelhantes, baseados na experiência dos autores e na observação de situações reais (GONZÁLEZ TERUEL, 2005). Os modelos são do âmbito teórico e os standards, também chamados de normas ou padrões, referem-se a aspectos práticos, que se levam a cabo através de competências, articuladas em categorias. Andretta (2005), Tomé (2008) e Uribe Tirado e Castaño Muñoz (2012) comparam várias normas, modelos e indicadores.

Descrevemos apenas alguns modelos e aplicações em contexto universitário, que se adaptam aos limites da presente pesquisa, como se pode observar no quadro 1:

Quadro 1. Modelos de competências em informação e suas aplicações.

\begin{tabular}{|l|l|}
\hline \multicolumn{1}{|c|}{ Modelo } & \multicolumn{1}{|c|}{ Aplicação } \\
\hline $\begin{array}{l}\text { Information Search Process de Carol } \\
\text { Kuhlthau (1993). EUA. }\end{array}$ & $\begin{array}{l}\text { Brasil. Estudantes. Realizado no Curso de } \\
\text { Biblioteconomia da Escola de Ciência da } \\
\text { Informação da Universidade Federal de } \\
\text { Minas Gerais. }\end{array}$ \\
\hline $\begin{array}{l}\text { The Seven Pillars of Information Literacy } \\
\text { de SCONUL (1999). Reino Unido. }\end{array}$ & $\begin{array}{l}\text { Reino Unido. Estudantes. Realizado nas } \\
\text { universidades: Abertay em Dundee; Cardiff; } \\
\text { Southampton; Wales em Newport; Bradford; } \\
\text { York (ILIAD Project). }\end{array}$ \\
\hline $\begin{array}{l}\text { Information Literacy Competency } \\
\text { Standards for Higher Education da ACRL } \\
\text { (2000). EUA. }\end{array}$ & $\begin{array}{l}\text { China. Estudantes. Realizado na Hong Kong } \\
\text { Baptist University. }\end{array}$ \\
\hline $\begin{array}{l}\text { (CI2) Competencias Informaticas e } \\
\text { Informacionales (2004). Espanha. }\end{array}$ & $\begin{array}{l}\text { Espanha. Estudantes. } \\
\text { universidades espanholas. }\end{array}$ \\
\hline $\begin{array}{l}\text { Empowering 8 do National Institute of } \\
\text { Library and Information Sciences (2004). } \\
\text { Sri Lanka. }\end{array}$ & $\begin{array}{l}\text { Indonésia. Estudantes. Realizado na Faculty } \\
\text { of Languages and Arts, State University of } \\
\text { Jakarta. }\end{array}$ \\
\hline
\end{tabular}

Fonte: Elaboração própria

Desde os anos 80 do século passado, que Carol Kuhlthau acompanha os estudantes na busca de informação e investiga sobre o ensino da pesquisa a partir da biblioteca. Baseando-se nas teorias construtivistas de Dewey, Kelly, Bruner e Vigotsky, propõe um modelo de processo de pesquisa da informação, Information Search Process (1993), inovador para a época, destinado a estudantes com mais de 12 anos, que abrange a esfera cognitiva (os pensamentos do sujeito em relação à tarefa que deve realizar), a esfera 
emocional (os sentimentos que o acompanham na evolução do seu pensamento), e esfera física (as ações que realiza e as estratégias que emprega).

A investigadora chama a atenção para a necessidade de acompanhar os estudantes nas fases mais difíceis do processo de busca, quando a informação encontrada não é pertinente ou suficiente ou demasiada e causadora de confusão. Esta abordagem reflete o percurso através do qual se desenvolvem as competências em informação nos estudantes e é composta por sete níveis: 1) Iniciação; 2) Seleção do tópico geral; 3) Exploração e seleção do tópico específico; 4) Formulação do tópico; 5) Recolha de informação; 6) Apresentação e 7) Avaliação.

Além disso, Kuhlthau analisou programas de competência em informação e identificou fatores determinantes do seu insucesso ou sucesso. As últimas investigações de Kuhlthau, em coautoria com Maniotes e Caspari, abordam as potencialidades do Guided Inquiry (2012) no desenvolvimento da competência em informação e, consequentemente, na preparação dos estudantes para as novas realidades da sociedade do conhecimento.

Baseando-se no modelo descrito, concretizou-se uma experiência, cujo objetivo era obter melhor compreensão sobre o desenvolvimento da competência em informação dos estudantes do Curso de Biblioteconomia da Escola de Ciência da Informação da Universidade Federal de Minas Gerais, no Brasil. No estudo foram observadas as habilidades, atitudes e conhecimentos relacionados com o desenvolvimento das diversas etapas, quando os estudantes elaboram trabalhos acadêmicos. Os dados permitiram identificar padrões relacionados com sentimentos, atitudes e ações relatadas e os resultados foram comparados com o modelo de Kuhlthau (CAMPELLO; ABREU, 2005).

A Society of College, National and University Libraries (SCONUL) do Reino Unido e Irlanda, através do seu Advisory Committee on Information Literacy, elaborou The SCONUL Seven Pillars of Information Literacy - Core Model For Higher Education (SCONUL, 1999), aprovado durante a Conference of National and University Libraries, e desenhado para estudantes universitários. 0 seu Information Skills Model define as habilidades e competências (habilidade) e atitudes e comportamentos (compreensão) que um estudante deve desenvolver 
ao longo do seu percurso educativo, para o desenvolvimento de competência em informação e compõe-se de sete etapas/pilares:

- reconhece necessidades de informação;

- consegue identificar formas de preencher essas necessidades;

- sabe construir estratégias para localizar informação;

- consegue localizar e acessar a informação;

- compara e avalia eficazmente a informação;

- organiza, aplica e comunica a informação de forma eficaz;

- é capaz de sintetizar e criar nova informação e novo conhecimento.

0 processo é progressivo, os estudantes vão passando de um nível para o seguinte, e progredindo a partir das competências básicas para o uso dos recursos informacionais e tecnológicos, até chegarem ao conceito mais elevado de competência em informação, em que detêm a consciência crítica e reflexiva que lhes permite usar a informação como um recurso intelectual. Por outro lado, cada pilar mostra uma interação através da qual o estudante progride na competência e capacidade de julgar com perícia a informação de que ele necessita, e, ao mesmo tempo, pratica as suas habilidades, elevando-as de acordo com as competências adquiridas ao longo do processo. Em 2011, o Working Group on Information Literacy, da mesma instituição, atualizou o modelo.

A aplicação do modelo SCONUL é relatada através de estudos de caso (SCONUL (2004), que envolvem numerosos estudantes das seguintes instituições, University of Abertay em Dundee, Cardiff University, University of Southampton, University of Wales em Newport, University of Bradford e University of York (ILIAD Project), no Reino Unido. A própria SCONUL decidiu divulgar as estratégias e as experiências destes programas, para que sejam úteis a outras instituições que necessitam desenvolver uma abordagem adequada à sua própria organização, ao aplicar programas de competência em informação.

A Association of College \& Research Libraries (ACRL), organização associada à American Library Association (ALA), lançou o Information Literacy Competency Standards for Higher Education: Standards, Performance Indicators, 
and Outcomes (ALA, 2000), que se converteu rapidamente numa referência mundial.

Os autores deste documento normativo consideram que a competência em informação é comum a todas as disciplinas, a todos os contextos de aprendizagem e a todos os níveis de ensino. 0 documento estabelece uma clara distinção entre competências em informação e competências tecnológicas e identifica uma série de competências que descrevem o processo informativo:

- determinar o alcance da informação;

- acessar de forma efetiva e eficiente;

- avaliar de forma crítica e incorporar a informação selecionada;

- usar de forma efetiva;

- entender os aspectos econômicos, legais e sociais e utilizar de forma ética e legal.

Esta proposta foi complementada com o documento Objectives for Information Literacy Instruction: A Model Statement for Academic Librarians (ALA/ACRAL, 2001), mais complexo, pois para além das cinco competências indicadas, abrange 22 indicadores de rendimento e 87 resultados observáveis, e serve de guia, tanto para os estudantes como para os docentes e os responsáveis das instituições acadêmicas.

Uma aplicação do modelo ACRL, que agora passamos a mencionar, resultou dos esforços institucionais em melhorar as competências e habilidades informacionais dos estudantes da Baptist University de Hong Kong, na China (CMOR, 2009). Considerado inovador para a época, o projeto mostra os esforços realizados e uma série de abordagens desenvolvidas com êxito, por bibliotecários universitários, e que fornecem orientação para experiências futuras.

O modelo Competencias Informaticas e Informacionales, cujo acrônimo é CI2, surge através do comitê formado pela Comissão Setorial de Tecnologias de Informação e Comunicações da Conferencia de Rectores de las Universidades Españolas (CRUE) e pela Red de Bibliotecas Universitarias (REBIUN). Esta proposta é destinada a incorporar as competências genéricas nas universidades 
espanholas, especialmente a evolução necessária para a competência em informação no contexto digital.

0 modelo corresponde à necessidade de adoção de estratégias com vista à integração das universidades no novo Espaço Europeu de Ensino Superior (EEES), resultante da assinatura do acordo de Bolonha em 1999, que visa tornar a Europa num espaço econômico mais dinâmico e competitivo, baseado no conhecimento, e capaz de garantir um crescimento econômico sustentável, com mais e melhores empregos e com maior coesão social.

Para alcançar este objetivo, o comitê publicou em 2008 e em 2012, um manual de apoio, Competencias informáticas e informacionales (CI2) en los estudios de grado, que se foi adotando gradualmente, e que define as seguintes competências:

- em relação ao computador e seus periféricos: compreende as partes mais comuns da máquina, identifica e compreende os componentes de um computador pessoal, periféricos e trabalha com os periféricos, cada vez mais complexos, e com mais funcionalidades;

- em relação aos programas: sabe instalar e configurar as aplicações mais comuns: aplicativos, navegadores, clientes de correio eletrônico, antivírus, etc., e conhece os principais programas a serem utilizados em cada área temática;

- em relação à rede: acessa a rede, conhece os recursos disponíveis na internet, navega de forma eficaz e conhece os benefícios e os riscos da web;

- em relação à informação:

a) busca as informações;

b) analisa e seleciona a informação, de forma eficiente;

c) organiza a informação corretamente;

d) utiliza e comunica a informação de forma eficaz, ética e legal, com o fim de construir conhecimento.

Além disso, o portal Web CI2, http://ci2.es/ disponibiliza produtos e materiais desenvolvidos pelo grupo de trabalho específico, bem como um 
espaço para a conexão com outros sites, portais, conteúdo e repositórios externos.

Tal como referimos anteriormente, praticamente todas as universidades espanholas aplicam o modelo CI2 e são numerosos os relatos de boas práticas de experiências de competência em informação, disponíveis na Web Foro Red Alfabetización Informacional do Ministério de Educación, Cultura y Deporte. A aplicação do modelo tem sido gradual, de acordo com o contexto de cada instituição.

O Empowering 8, popularmente chamado E8, é um modelo resultante de dois seminários: o primeiro em Colombo, Sri Lanka, em novembro de 2004 e o segundo em Patiala, na Índia, em novembro de 2005. Neles participaram dez países asiáticos, Bangladesh, Índia, Indonésia, Maldivas, Malásia, Nepal, Paquistão, Singapura, Sri Lanka, Tailândia e Vietnã, liderados pelo National Institute of Library and Information Sciences (NILIS) de Sri Lanka. Singh (2008) descreve esta proposta, que usa a abordagem de resolução de problemas para a aprendizagem baseada em recursos, e abarca as seguintes oito habilidades:

- identificar um tema/assunto, o público-alvo, um formato relevante, palavras-chave, tipos de recursos;

- explorar recursos e informações;

- selecionar e gravar as informações relevantes, identificar as fases do processo, e recolher citações apropriadas;

- organizar, avaliar e usar os organizadores visuais para comparar e contrastar informações;

- criar informações usando próprias palavras;

- compartilhar e apresentar informações;

- avaliar a produção;

- aplicar as soluções baseadas no feedback e na avaliação e utilizar novo conhecimento adquirido em situações variadas.

A originalidade deste modelo é ter sido desenvolvido por asiáticos para asiáticos. Durante os seminários referidos destacou-se que o sucesso da 
competência em informação na Ásia depende em grande parte da liderança das bibliotecas e dos profissionais de informação da região.

A aplicação deste modelo foi realizada a estudantes da Faculty of Languages and Arts, State University of Jakarta, na Indonésia (BOERISWATI, 2012). Os resultados apresentados diferem, conforme o ciclo de estudos a que os estudantes pertencem, mas coincidem ao considerar influentes em competência em informação as suas atitudes em relação à inovação e autoconfiança.

Em Understanding Information Literacy: a Primer (2007), Forest Horton, refere que os modelos existentes têm em comum o fato de possuírem várias etapas ou níveis, através dos quais avança o processo da aquisição das competências em informação, progressivo e sequencial. Cada modelo procura dar resposta a necessidades concretas, mas todos eles têm o mérito de propor estratégias que permitem construir um enfoque próprio para a resolução de problemas, com recurso à informação, desenvolver o pensamento crítico, reforçar a autonomia, e tornar os cidadãos ativos da sua própria aprendizagem.

Os cinco modelos de competência em informação apresentados são apenas alguns dos inúmeros identificados na bibliografia, cuja abundância prova o interesse de investigadores, docentes e profissionais da informação, ainda que a abordagem e complexidade possam ser ligeiramente diferentes. Além disso, todos ressaltam o papel fundamental dos bibliotecários e das bibliotecas universitárias para se conseguir concretizar, com êxito, qualquer dos modelos. Por outro lado, a seleção dos modelos e das aplicações não foi arbitrária, sendo condicionadas pelo interesse em divulgar diferentes tipos de experiências em contexto universitário a nível mundial, algumas das quais pouco divulgadas. Podemos concluir o estudo sobre modelos e sua aplicação, observando os seguintes aspectos:

- a diversidade cronológica dos modelos, desde 1993 até 2004, permitindo constatar o desenvolvimento nas atividades de profissionais e de pesquisadores na área de competência em informação, num período de dez anos; 
- a diversidade geográfica da origem dos modelos (América do Sul, Europa, EUA e Ásia);

- a tipologia de criação de modelos: individual (Kuhlthau) e coletiva (SCONUL, ACRL, CI2 e E8).

Quanto à aplicação dos modelos, ressaltamos:

- a diversidade geográfica (América do Sul, Europa, EUA e Ásia) e a diversidade de tipo de instituição: públicas (Brasil, Reino Unido e Indonésia), públicas e privadas (Espanha) e privada (China).

- a diversidade de aplicação, a saber: a) um modelo aplicado a estudantes de um só curso universitário (Kuhlthau, Brasil); b) um modelo aplicado a estudantes de uma única faculdade (E8/Indonésia); c) um modelo aplicado a estudantes de uma única universidade (ACRL/China); d) um modelo aplicado em programas realizados em várias universidades (SCONUL/Reino Unido e CI2/Espanha);

- a diversidade de políticas informacionais e educacionais em universidades e países, bem como de projetos e programas.

A literatura sobre competência em informação comprova, segundo Byrne (2005), divergência e alguma tensão entre dois grupos com perspectivas diametralmente opostas. Os teóricos ou puristas, que expressam uma visão coerente e compreendem o processo de aprendizagem através do qual se pode desenvolver. Argumentam que a competência em informação pode ser desenvolvida e expressa apenas dentro de um contexto, e que a aplicação do conceito difere de um campo do conhecimento para outro. Nesta perspectiva, os programas genéricos, por serem descontextualizados, só podem promover aprendizagem de baixo nível. Os pragmáticos, que enfatizam as habilidades específicas e o seu desenvolvimento, bem como os resultados mensuráveis através de programas adaptáveis a vários contextos. Talvez demasiado centrados em soluções rápidas, os defensores desta postura estão conscientes da necessidade de desenvolver a competência em informação em situações muito diversificadas. 


\section{CONSIDERAÇÕES FINAIS}

A produção científica assinala a universalidade do paradigma de desenvolvimento de competências em informação para o século XXI e a necessidade da sua inclusão nos conteúdos dos diferentes níveis de educação ao longo da vida.

A maioria dos autores coincide em considerar que o crescimento exponencial da informação não significa obrigatoriamente uma melhoria da qualidade na busca e uso da mesma, principalmente se se comparam regiões, países e pessoas.

Os cinco modelos de competência em informação que acabamos de apresentar são alguns dos que obtiveram êxito em contexto universitário em diferentes regiões, e que não excluem a validade de outros, sempre quando adaptados às necessidades de informação das diferentes comunidades acadêmicas. Além disso, todos os autores dos modelos ressaltam o papel fundamental dos bibliotecários e das bibliotecas universitárias para se conseguir concretizar, de forma positiva, qualquer deles.

Para alcançar esse objetivo, compete aos bibliotecários, docentes, investigadores e instituições documentais e educativas proporcionarem o desenvolvimento de competências e habilidades para procurar, encontrar, avaliar e usar a informação apropriada e de forma ética.

Por outro lado, a seleção dos modelos e das aplicações não foi arbitrária, sendo condicionada pelo interesse em divulgar diferentes tipos de experiências em contexto universitário a nível mundial, algumas das quais pouco divulgadas.

Durante as quatro últimas décadas, muitos autores e investigadores têm vindo a oferecer diferentes conceitos, definições e perspectivas sobre competência em informação, necessária para o cidadão enfrentar com dignidade a vida. Por conseguinte, a competência em informação é um termo vivo e em contínua evolução. As distintas propostas são complementares entre si, na medida em que procuram um fim comum, a formação integral do indivíduo, que lhe permita a sua participação consciente e ativa na sociedade. 
Todos os cidadãos devem ter acesso à informação, desenvolverem-se de forma holística, contribuir para o desenvolvimento dos seus países, diminuindo a brecha digital e social, e participar da nova sociedade globalizada, baseada no conhecimento e na aprendizagem ao longo da vida.

\section{REFERÊNCIAS}

ANDRETTA, S. Information literacy: a practitioner's guide Oxford: Chandos Publishing, 2005.

ASSOCIATION OF COLLEGE \& RESEARCH LIBRARIES (ACRL). Information Literacy Competency Standards for Higher Education, da Association of College \& Research Libraries. 2000. Disponível em: <http://www.ala.org/ala/mgrps/divs/acrl/standards/informationliteracycomp etency.cfm>. Acesso em: 20 abr. 2014.

BAWDEN, D. Revisión de los conceptos de alfabetización Informacional y alfabetización digital. Anales de Documentación, n.5, p.361-408, 2002. Disponível em:

<http://revistas.um.es/index.php/analesdoc/article/viewFile/2261/2251>. Acesso em: 20 abr. 2014.

BEHRENS, S. J. A conceptual analysis and historical overview of information literacy. College \& Research Libraries, v.55, n. 4, p.309-323, 1994. Disponível em: <https://www.ideals.illinois.edu/handle/2142/41773>. Acesso em: 20 abr. 2014.

BERNHARD, P. Apprendre à maîtriser l'information : des habiletés indispensables dans une société du savoir ? Éducation et francophonie, v.26, n.1, 1998. Disponível em : <http://www.acelf.ca/c/revue/pdf/09BERNHARD_vf.pdf $>$. Acesso em: 20 abr. 2014.

La formación en el uso de la información: una ventaja en la enseñanza superior. Situación actual. Anales de Documentación, n.5, p.409-435, ene. 2002. Disponível em: <http://revistas.um.es/analesdoc/article/view/2271/2261>. Acesso em: 20 abr. 2014.

BHOLA, H. L. Literacy. In: FEATHER, J.; STURGES, P. (eds.). International Encyclopaedia of Information and Library Science. London: Routledge, 1997. p. 277-280.

BOERISWATI, E. The implementing model of Empowering Eight for Information Literacy. 2012. Disponível em: <http://files.eric.ed.gov/fulltext/ED535495.pdf>. Acesso em: 24 abr. 2014. 
BYRNE, A. La alfabetización informacional desde una perspectiva global: el desastre agudiza nuestras mentes. Anales de Documentación, n.8, p.7-20, 2005. Disponível em: <http://revistas.um.es/analesdoc/article/view/1571>. Acesso em: 24 abr. 2014.

CALZADA PRADO, F. J.; MARZAL, M. Á. Quince años de alfabetización en información: investigación internacional recogida en LISA, ERIC y SSCI entre 1990 y 2005. Boletín de la Asociación Andaluza de Bibliotecarios, v.22, n.86-87, p.15-27, enero-junio, 2007. Disponível em:

<http://doteine.uc3m.es/docs/CalzadaMarzal_BAAB07.pdf>. Acesso em: 28 abr. 2014.

CAMPELLO, B; ABREU, V. L. F. G. Competência informacional e formação do bibliotecário. Perspect. Ciênc. Inf., Belo Horizonte, v.10, n.2, p. 178-193, jul./dez. 2005. Disponível em: <http://www.brapci.ufpr.br/download.php?dd0=12102>. Acesso em: 28 abr. 2014.

CMOR, D. Campus priorities and information literacy in Hong Kong Higher Education: a case study. Library Management, v.30, n.8/9, p.627-642, 2009. Disponível em:

<http://repository.hkbu.edu.hk/cgi/viewcontent.cgi?article=1003\&context=lib_ ja. $>$. Acesso em: 28 abr. 2014.

CRUE/REBIUN. Manual para la formación en competencias informáticas e informacionales (CI2), 2013. Disponível em:

<http://ci2.es/sites/default/files/documentacion/manual_ci2_completo.pdf>. Acesso em: 24 abr. 2014.

DUPLESSIS. P. et al. Inventaire des concepts info-documentaires mobilisés dans les activités de recherche d'informa-tions en ligne. Nantes: Académie, 2005.

Disponível em: <http://www.ac-

nantes.fr:8080/peda/disc/cdi/reseau/crjrl05/jrl49-4.pdf>. Acesso em: 24 abr. 2014.

DUZDIAK, E A. Infomation literacy: princípios, filosofia e prática. Ciência da Informação, Brasília, v.32, n.1, p.23-35, jan./abr. 2003. Disponível em: <http://revista.ibict.br/ciinf/index.php/ciinf/article/view/123>. Acesso em: 28 abr. 2014.

GASQUE, K. C. G. D. Letramento informacional: pesquisa, reflexão e aprendizagem (e-book). Brasília: Universidade de Brasília, Faculdade de Ciência da Informação, 2012. Disponível em:

<http://repositorio.unb.br/handle/10482/13025>. Acesso em: 8 abr. 2014.

GONZÁLEZ TERUEL, A. Los estudios de necesidades y usos de la información: fundamentos y perspectivas actuales. Gijón: Ediciones Trea, 2005. 
IFLA. Declaração de Alexandria sobre competência informacional e aprendizado ao longo da vida. 2005. Disponível em:

<http://archive.ifla.org/III/wsis/BeaconInfSoc-pt.html>. Acesso em: 28 abr. 2014.

Media and information literacy recommendations. 2008. Disponível em: $<$ http://www.ifla.org/en/ifla-media-andinformationliteracyrecommendations>. Acesso em: 28 abr. 2014.

KHAN. Preface. Towards Information Literacy Indicators. In: CATTS, Ralph; LAU, Jesus. Paris: UNESCO, 2008. Disponível em:

<http://www.uis.unesco.org/Library/Documents/wp08_InfoLit_en.pdf>. Acesso em: 28 abr. 2014.

KUHLTHAU, C. Information Search Process (1985-2008). Last Updated October 2013. Disponível em:

<http://comminfo.rutgers.edu/ kuhlthau/information_search_process.htm>. Acesso em: 28 abr. 2014.

KUHLTHAU, C. C.; MANIOTES, L. K.; CASPARI, A. K. Guided inquiry design: a framework for inquiry in your school. Santa Barbara, California: Libraries Unlimited, 2012.

LAU, J. Conceptual relationship of information literacy and media literacy in knowledge societies. Series of Research Papers, WSIS+10 Review. Paris: UNESCO, 2013. Disponível em:

<http://www.unesco.org/new/fileadmin/MULTIMEDIA/HQ/CI/CI/pdf/wsis/ WSIS_10_Event/WSIS_Series_of_research_papers_Conceptual_Relationship_bet ween_Information_Literacy_and_Media_Literacy.pdf\#page $=103 \geq$. Acesso em: 28 abr. 2014.

LE DEUFF, O. La culture de l'information : quelles littératies pour quelles conceptions de l'information? In : VIème Colloque ISKO-France'2007, IUT. Université Paul Sabatier : Toulouse, 2007.

LIMBERG, L.; SUNDIM, O.; TALJA, S. In human IT. Journal for Information Technology Studies as a Human Science, v.11, n.2, p.91-128, 2012. Disponível em: <http://etjanst.hb.se/bhs/ith/2-11/llosst.pdf>. Acesso em: 28 abr. 2014.

MACKEY, T. P.; JACOBSON, T. E. Reframing information literacy as a metaliteracy. College \& Research Libraries, v.72, n.1, p.62-78, 2011. Disponível em: <http://crl.acrl.org/content/72/1/62.full.pdf+html>. Acesso em: 28 abr. 2014.

MARKLESS, S; STREATFIELD, D. R. Three decades of information literacy: redefining the parameters. In: Andretta, S. (ed.) Change and challenge: information literacy for the 21stCentury. Adelaide: Auslib Press, 2007. 
MARZAL, M. Á. Evolución conceptual de la alfabetización en información a partir de la alfabetización múltiple en su perspectiva educativa y bibliotecaria. Investigación Bibliotecológica, v23, n.47, p.129-160, 2009. Disponível em: $\leq$ http://dialnet.unirioja.es/servlet/articulo?codigo $=3216649>$. Acesso em: 28 abr. 2014.

. La evaluación de los programas de alfabetización en información en la educación superior: estrategias e instrumentos. Revista de universidad y sociedad de conocimiento, v.7, n.2, 2010. Disponível em:

<http://rusc.uoc.edu/ojs/index.php/rusc/article/view/v7n2-marzal/v7n2marzal>. Acesso em: 28 abr. 2014.

MORING, C.; LLOYD, A. Analytical implications of using practice theory in workplace information literacy research. Information Research, v.18, n.3, 2013. Disponível em: <http://www.informationr.net/ir/18-3/colis/paperC35.html>. Acesso em: 28 abr. 2014.

THE NEW LONDON GROUP. A pedagogy of multiliteracies: designing social futures. Harvard Educational Review, v.66, n.1, Spring, 1996. Disponível em: $<$ http://newlearningonline.com/_uploads/multiliteracies_her_vol_66_1996.pdf $>$. Acesso em: 28 abr. 2014.

PINTO, M.; CORDÓN, J. A.; GÓMEZ, R. Thirty years of information literacy (19772007): a terminological, conceptual and statistical analysis. Journal of Librarianship and Information Science, v.42, n.1, p.3-19, 2010. Disponível em: <http://lis.sagepub.com/content/42/1/3.short>. Acesso em: 28 abr. 2014.

PINTO, M. Alfabetización informativo-digital. E-COMS. Atualização em 13/04/2011. Disponível em: <http://www.mariapinto.es/ecoms/alfa_infor.htm>._Acesso em: 28 abr. 2014.

SINGH, J. Sense-making: information literacy for lifelong. Learning and knowledge management. DESIDOC Journal of Library \& Information Technology, v.28, n.2, p.03-07, 2008. Disponível em:

<http://webcache.googleusercontent.com/search?q=cache:r99ArL3vv9QJ:publi cations.drdo.gov.in/ojs/index.php/djlit/article/viewFile/161/74+\&cd=1\&hl=es \&ct=clnk\&gl=pt>. Acesso em: 28 abr. 2014.

SCONUL. Information skills in higher education: a SCONUL position paper. 1999. Disponível em:

<http://www.sconul.ac.uk/groups/information_literacy/seven_pillars.html>. Acesso em: 28 abr. 2014.

The Seven Pillars of information literacy model. 2004. Disponível em: <http://www.sconul.ac.uk/groups/information_literacy/seven_pillars.html>. Acesso em: 28 abr. 2014. 
. Learning outcomes and information literacy. 2004. Disponível em:

<http://www.sconul.ac.uk/sites/default/files/documents/outcomes.pdf>. Acesso em: 28 abr. 2014.

. The SCONUL Seven Pillars of information literacy: core model. For higher education. 2011. Disponível em:

<http://www.sconul.ac.uk/sites/default/files/documents/coremodel.pdf>. Acesso em: 28 abr. 2014.

TOMÉ, M.C. A biblioteca escolar e o desafio da literacia da informação: um estudo empírico no Distrito de Viseu. 225f. Dissertação (Mestrado em Gestão da Informação e Bibliotecas Escolares) - Departamento de Ciências da Educação, Universidade Aberta, Lisboa, 2008. Disponível em: <https://repositorioaberto.uab.pt/bitstream/10400.2/1222/1/Tese.pdf>. Acesso em: 28 abr. 2014.

URIBE-TIRADO, A. Interrelaciones entre veinte definiciones-descripciones del concepto de alfabetización informacional: propuesta de macro-definición. ACIMED, v.20, n.4, 2009. Disponível em: <http://bvs.sld.cu/revistas/aci/vol20_4_09/aci011009.pdf>. Acesso em: 28 abr. 2014.

URIBE-TIRADO, A; CASTAÑO MUÑOZ, W. Information literacy competency standards for higher education and their Correlation with the cycle of knowledge generation. LIBER Quarterly, v.22, n.3, 2012. Disponível em: <https://liber.library.uu.nl/index.php/lq/article/view/URN\%3ANBN\%3ANL\% 3AUI\%3A10-1-113941/8568>. Acesso em: 28 abr. 2014.

URIBE-TIRADO, A; URIBEII, A. La alfabetización informacional en las bibliotecas universitarias de Portugal. Visualización de los niveles de incorporación desde la información publicada en sus sitios Web. PRISMA.COM, n.15, 2011. Disponível em: <http://eprints.rclis.org/16563/1/1091-4323-1-PB.pdf>. Acesso em: 28 abr. 2014.

UNESCO. Media and information literacy. 2008. Disponível em: <http://portal.unesco.org/ci/en/ev.phpURL_ID=15886\&URL_DO=DO_TOPIC\&U RL_SECTION=201.html>. Acesso em: 28 abr. 2014.

. Teacher training curricula for media and information literacy. Report of the International Expert Group Meeting. 2008. Disponível em:

$<$ http://portal.unesco.org/ci/en/ev.phpURL_ID=27057\&URL_DO=DO_TOPIC\&URL_SECTION=201.html>. Acesso em: 28 abr. 2014.

UNESCO/IFLA. Declaração de Alexandria sobre competência informacional e aprendizado ao longo da vida. 2005. Disponível em: <http://archive.ifla.org/III/wsis/BeaconInfSoc-pt.html>. Acesso em: 28 abr. 2014. 
VIRKU, S. Information literacy in Europe: a literature review. Information Research, v.8, n.4, 2003. Disponível em: <http://informationr.net/ir/84/paper159.html>. Acesso em: 28 abr. 2014.

ZURKOWSK, P.G. The information service environment relationships and priorities, related paper $N^{\circ} 5$. Washington, DC, National Program for Library and Information Services, 1974. Disponível em:

<http://eric.ed.gov/PDFS/ED100391.pdf>. Acesso em: 28 abr. 2014. 
